\title{
Seedling Ecology and Evolution
}

Seedlings are highly sensitive to their environment. After seeds, seedlings typically suffer the highest mortality rate of any life history stage. This book provides a thoughtful and comprehensive review by leading researchers of the interconnected topics that constitute seedling ecology and ecophysiology, focusing on how and why seedlings are successful. It considers the importance of seedlings in plant communities; environmental factors with special impact on seedlings; the morphological and physiological diversity of seedlings, including mycorrhizae; the relationship of the seedling with other life stages; seedling evolution; and seedlings in human-altered ecosystems, including deserts, tropical rainforests, and habitat-restoration projects. The diversity of seedlings is portrayed by specialized groups, such as orchids, bromeliads, and parasitic and carnivorous plants. This important text sets the stage for future research and is valuable to graduate students and researchers in plant ecology, botany, agriculture, and conservation.

The editors are well known for their work in soil seed-bank ecology. Mary Allessio Leck, Emeritus Professor of Biology, Rider University, has worked on seed ecology of tidal freshwater wetland species, and on wetland education for urban youth; V. Thomas Parker, Professor of Biology, San Francisco State University, on tidal wetland, chaparral, and mycorrhizal ecology, and Arctostaphylos evolution; and Robert L. Simpson, Professor of Biology and Environmental Science, University of Michigan - Dearborn, on freshwater wetland ecology and the natural history of Michigan. 


\section{Seedling Ecology and Evolution}

\section{Editors}

Mary Allessio Leck

Emeritus Professor of Biology, Rider University, USA

\section{Thomas Parker}

Professor of Biology, San Francisco State University, USA

\section{Robert L. Simpson}

Professor of Biology and Environmental Science, University of Michigan - Dearborn, USA 
CAMBRIDGE UNIVERSITY PRESS

Cambridge, New York, Melbourne, Madrid, Cape Town, Singapore, São Paulo, Delhi

Cambridge University Press

The Edinburgh Building, Cambridge CB2 8RU, UK

Published in the United States of America by Cambridge University Press, New York www.cambridge.org

Information on this title: www.cambridge.org/9780521873055

(C) Cambridge University Press 2008

This publication is in copyright. Subject to statutory exception and to the provisions of relevant collective licensing agreements, no reproduction of any part may take place without the written permission of Cambridge University Press.

First published 2008

Printed in the United Kingdom at the University Press, Cambridge

A catalog record for this publication is available from the British Library

ISBN 978-0-521-87305-5 hardback

ISBN 978-0-521-69466-7 paperback

Cambridge University Press has no responsibility for the persistence or accuracy of URLs for external or third-party Internet Web sites referred to in this publication, and does not guarantee that any content on such Web sites is, or will remain, accurate or appropriate. 


\section{Contents}

Contributors

page $\mathrm{xi}$

Foreword by Peter J. Grubb

Preface

\section{Part I Introduction}

\begin{tabular}{lr}
\hline Chapter I & Why seedlings? \\
& Mary Allessio Leck, Robert L. Simpson, and \\
V. Thomas Parker & 3 \\
1.1 & Seedlings as part of a plant's life cycle \\
1.2 Vulnerabilities and bottlenecks & 6 \\
1.3 Making it: filters, safe sites, and establishment & 8 \\
1.4 Seedlings: a primer & 10 \\
1.5 & What seedlings can tell us \\
1.6 & The scope of Seedling Ecology and Evolution
\end{tabular}

\section{Part II Seedling diversity}

\section{Chapter 2 Seedling natural history}

Mary Allessio Leck and Heather A. Outred

2.1 Introduction

2.2 The seedling stage and fate of seedlings 17

2.3 Seedling types 20

2.4 Seedling diversity - morphology 24

2.5 Seedling diversity - ecophysiology 31

2.6 Vivipary and seedling equivalents 33

2.7 Longevity 36

2.8 Dispersal 37

2.9 Environmental filters and safe sites 38

2.10 Summary $\quad 41$

2.11 Acknowledgments $\quad 41$

Appendixes 42

Chapter 3 Specialized seedling strategies I: seedlings in stressful environments

3.1 Introduction

José M. Facelli

3.2 Seedling establishment in dense shade 60

3.3 Effects of litter on seedling establishment 64

3.4 Seedling establishment in dry environments 65

3.5 Seedling establishment in saline environments 68 
3.6 Seedling establishment in cold environments

3.7 Physical damage to seedlings

3.8 Interactive effects of stress agents and biological interactions

3.9 Overview: adaptations of seedlings to stressful environments

Chapter 4 Specialized seedling strategies II: orchids, bromeliads, carnivorous plants, and parasites

Dennis F. Whigham, Melissa K. McCormick, and John P. O'Neill

4.1 Introduction

4.2 Epiphytic and terrestrial orchids

4.3 Bromeliads

4.4 Carnivorous plants

4.5 Parasitic plants

4.6 Summary and future needs

4.7 Acknowledgments

\section{Part III Seedling morphology, evolution,} and physiology

Chapter 5 Embryo morphology and seedling evolution

5.1 Introduction

Karl J. Niklas

5.2 Embryophyte phylogeny

5.3 Embryo structure

5.4 Embryophyte embryogenesis

5.5 Phylogenetic patterns

Chapter 6 Regeneration ecology of early angiosperm seeds and seedlings: integrating inferences from extant basal lineages and fossils

Taylor S. Feild

6.1 Introduction

6.2 Previous views of ancestral angiosperm ecology and seed/seedling morphology

6.3 The phylogenetic revolution: inferences on early angiosperm regeneration ecology from extant basal angiosperms

6.4 Functional biology of basal angiosperm seeds

6.5 Functional biology of basal angiosperm seedlings

6.6 Outlook and recommendations for future research 


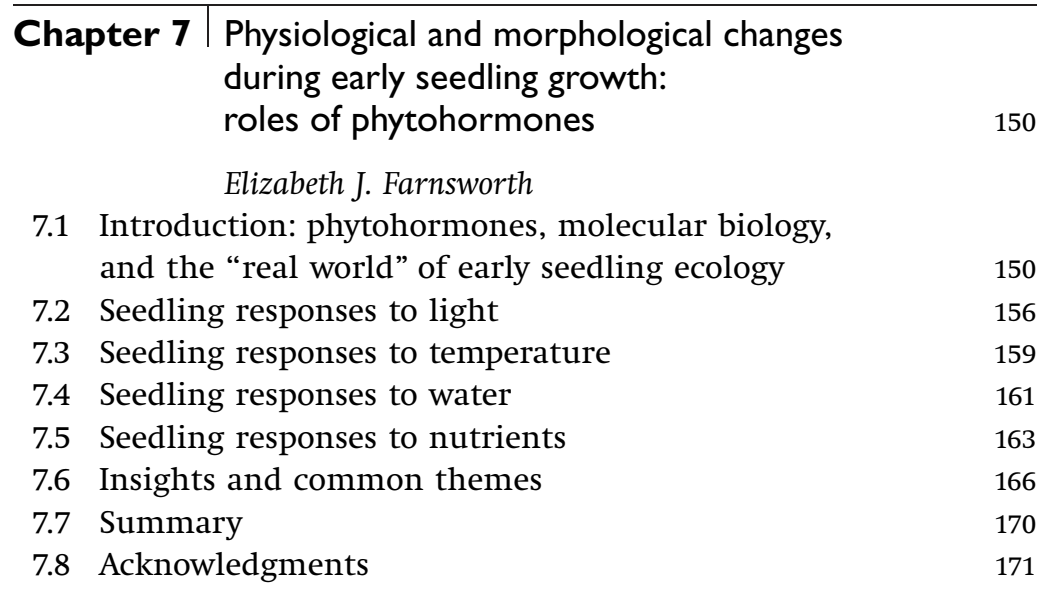

\section{Chapter 8 Seedling ecophysiology: strategies toward} achievement of positive net carbon balance

Kaoru Kitajima and Jonathan A. Myers

8.1 Introduction

8.2 Seed reserve utilization 173

8.3 Ontogenetic trajectories of seedling carbon balance 175

8.4 Species differences in inherent relative growth rate (RGR)

177

8.6 Carbohydrate reserves

8.7 Phenotypic plasticity 185

8.8 Concluding remarks 187

8.9 Acknowledgments 188

\begin{tabular}{l|lr}
\hline Chapter 9 & $\begin{array}{l}\text { The role of symbioses in seedling } \\
\text { establishment and survival }\end{array}$ & 189 \\
$\quad$ Thomas R. Horton and Marcel G. A. van der Heijden & \\
& & 189 \\
9.1 & Introduction & 199 \\
9.2 & Ectomycorrhizal fungi and seedling establishment & \\
9.3 Arbuscular mycorrhizal fungi and seedling & 207 \\
& establishment & 209 \\
9.4 & Other plant symbionts and seedling establishment & 212 \\
9.5 Conclusions & 213 \\
9.6 Acknowledgments
\end{tabular}

\section{Part IV Life history implications}

\begin{tabular}{c|l}
\hline Chapter I0 & $\begin{array}{l}\text { The seedling as part of a plant's life } \\
\text { history strategy }\end{array}$ \\
$\quad$ Angela T. Moles and Michelle R. Leishman & 217 \\
$10.1 \quad$ Introduction &
\end{tabular}


10.2 The trade-off between offspring production and seedling survival

10.3 Understanding seed and seedling ecology as parts of a plant's life history strategy

10.4 Correlations between seed and seedling strategy and other aspects of plant ecology

10.5 Seed and seedling strategies within species

10.6 Implications of a holistic understanding of plant life history strategies

10.7 Conclusions

Chapter I I Seedling recruitment and population ecology

Ove Eriksson and Johan Ehrlén

11.1 Introduction

11.2 The causes of seedling mortality

11.3 Recruitment limitation

11.4 Seedling recruitment and population dynamics

11.5 Genetic structure and selection in seedling populations

11.6 Concluding remarks

11.7 Acknowledgments

Chapter I2 1 Seedling communities

12.1 Introduction

Jon E. Keeley and Phillip J. van Mantgem

12.2 Internal drivers

12.3 External drivers affecting seedling communities

12.4 Seedling community assembly rules

12.5 Conclusions

Chapter I3 1 Spatial variation in seedling emergence and establishment - functional groups among and within habitats?

Johannes Kollmann

13.1 Introduction

13.2 Description of the seedling stage

13.3 Definition of spatial scales

13.4 Microhabitat effects on seedling dynamics 280

13.5 Habitat effects on seedling dynamics 282

13.6 Landscape effects on seedling dynamics 285

13.7 Region effects on seedling dynamics 286

13.8 Biome effects on seedling dynamics: seed size and seedling survival

13.9 Synthesis 


\section{Part V Applications}

\section{Chapter I4 1 Does seedling ecology matter for} biological invasions?

Laura A. Hyatt

14.1 Introduction

14.2 Invasive seedlings

14.3 Invasive effects on native seedlings 303

$\begin{array}{ll}14.4 \text { Conclusions } & 305\end{array}$

14.5 Acknowledgments 306

\begin{tabular}{l|l}
\hline Chapter I5 & The role of seedlings in the dynamics of
\end{tabular} dryland ecosystems - their response to and involvement in dryland heterogeneity, degradation, and restoration

Bertrand Boeken

15.1 Introduction

15.2 Importance of the seedling stage 308

15.3 Seedlings and spatial heterogeneity of drylands 312

15.4 Seedlings and dryland system degradation 322

15.5 Conclusions 330

Chapter 16 Anthropogenic disturbance in tropical forests: toward a functional understanding of seedling responses

James W. Dalling and David F. R. P. Burslem

16.1 Introduction

16.2 Significance of the seedling stage for forest management

16.3 Effects of human disturbances on seedling regeneration

16.4 Application of seedling functional ecology to tropical forest management and restoration

16.5 Future directions

\section{Chapter 17 Seedling establishment in restored} ecosystems

Susan Galatowitsch

17.1 Introduction

17.2 Selecting initial community composition for restoration

17.3 Creating safe sites to promote seedling establishment 359

17.4 Managing biotic interactions that affect seedling survival and growth 
Cambridge University Press

978-0-521-87305-5 - Seedling Ecology and Evolution

Edited by Mary Allessio Leck, V. Thomas Parker and Robert L. Simpson

Frontmatter

More information

17.5 Mimicking the effects of disturbances in restoration

\section{Part VI Synthesis}

Chapter 18 The seedling in an ecological and evolutionary context

V. Thomas Parker, Robert L. Simpson, and Mary Allessio Leck

18.1 Introduction

18.2 Dispersal, seed bank dynamics, and seedling banks

18.3 Dynamics of individual seedlings

18.4 Seedlings in heterogeneous environments

18.5 Alternative strategies

18.6 Conclusions 


\section{Contributors}

\section{Bertrand Boeken}

Ben-Gurion University of the Negev

The Wyler Department of Dryland Agriculture Jacob Blaustein Institutes Sede Boker Campus for Desert Research

Ben-Gurion, Israel

David F. R. P. Burslem

University of Aberdeen

Department of Plant and Soil Science

Aberdeen, Scotland, UK

James W. Dalling

University of Illinois, Urbana-Champaign

Department of Plant Biology

Urbana, Illinois, USA

\section{Johan Ehrlén}

Stockholm University

Department of Botany

Stockholm, Sweden

\section{Ove Eriksson}

Stockholm University

Department of Botany

Stockholm, Sweden

José M. Facelli

The University of Adelaide

Discipline of Ecology and Evolutionary Biology

School of Earth and Environmental Sciences

Adelaide, Australia

\section{Elizabeth J. Farnsworth}

New England Wild Flower Society

Framingham, Massachusetts, USA

\section{Taylor S. Feild}

The University of Tennessee

Ecology and Evolutionary Biology

Knoxville, Tennessee, USA

\section{Susan Galatowitsch}

University of Minnesota

Department of Horticultural Science

St. Paul, Minnesota, USA

\section{Peter J. Grubb}

University of Cambridge

Department of Plant Sciences

Cambridge, UK

\section{Thomas R. Horton}

State University of New York

College of Environmental Science and Forestry

Syracuse, New York, USA

\section{Laura A. Hyatt}

Rider University

Biology Department

Lawrenceville, New Jersey, USA

Jon E. Keeley

United States Geological Survey

Sequoia and Kings Canyon Field Station

Three Rivers, California, USA

and

University of California - Los Angeles

Department of Ecology and Evolutionary Biology

Los Angeles, California, USA

\section{Kaoru Kitajima}

University of Florida

Department of Botany

Gainesville, Florida, USA

and

Smithsonian Tropical Research Institute

Apartado, Balboa, Panama 


\section{Johannes Kollmann}

University of Copenhagen

Department of Agriculture and Ecology

Frederiksberg C, Denmark

\section{Mary Allessio Leck}

Rider University

Biology Department

Lawrenceville, New Jersey, USA

\section{Michelle R. Leishman}

Macquarie University

Department of Biological Sciences

Sydney, Australia

\section{Melissa K. McCormick}

Smithsonian Environmental

Research Center

Edgewater, Maryland, USA

\section{Angela T. Moles}

University of New South Wales

School of Biological, Earth, and

Environmental Sciences

Sydney, Australia

\section{Jonathan A. Myers}

Louisiana State University

Department of Biological Sciences

Division of Systematics, Ecology, and

Evolution

Baton Rouge, Louisiana, USA

\section{Karl J. Niklas}

Cornell University

Department of Plant Biology

Ithaca, New York, USA
John P. O'Neill

Smithsonian Environmental Research Center

Edgewater, Maryland, USA

\section{Heather A. Outred}

Massey University

College of Science

Institute of Molecular Biosciences

Palmerston North, New Zealand

\section{Thomas Parker}

San Francisco State University

Department of Biology

San Francisco, California, USA

\section{Robert L. Simpson}

The University of Michigan - Dearborn

Department of Natural Sciences

Dearborn, Michigan, USA

Marcel G. A. van der Heijden

Agroscope Reckenholz-Tanikon Research

Station ART

Zurich, Switzerland

Phillip J. van Mantgem

United States Geological Survey

Sequoia and Kings Canyon Field

Station

Three Rivers, California, USA

\section{Dennis F. Whigham}

Smithsonian Environmental Research Center

Edgewater, Maryland, USA 


\section{Foreword}

The properties of seedlings are potentially important to all plant ecologists, whether they be interested chiefly in understanding seminatural indigenous vegetation, invasive plants, or the problems of restoration. In seminatural vegetation, seedling properties may determine the climatic regions occupied on a continental scale and the habitats occupied within a landscape, the ability of one species to coexist with another in a community, and the abundance of one species relative to another at a given time and place. The requirements of seedlings often determine the sites in which potentially invasive species can succeed and whether a given approach to restoration of seminatural vegetation is effective.

During the last 40 years, there has been a steady increase in the amount of research by ecologists on the properties of seedlings as opposed to those of mature plants. Great pioneers such as F. E. Clements and E. J. Salisbury appreciated the importance of studying seedlings, although papers on experimental studies on seedlings were uncommon before the 1960s. Several factors have driven the increase in work on seedlings. Here I emphasize seven.

First, there has been a desire to seek generalizations about seedlings. For example, how does relative growth rate vary with the mass of reserves in the seed, and how does it differ at a given seed-reserve mass between plants of different growth forms (such as tree vs. herb), or species from different kinds of habitat (where the vegetation shows high and low productivity, respectively)? For the mechanistically minded, the key questions become (1) how do seedlings of species with smaller seeds have higher relative growth rates, and (2) how do species of different functional types have different relative growth rates at a given seed-reserve mass? Of course, the answers to these questions have turned out to be related to our increased understanding of the ecophysiology of the vegetative organs of the adult plant, at least of the leaves - there still is much to learn regarding stems and roots.

Second, there has been a realization that differences among species with regard to the requirements of juveniles may play a significant role in making possible long-term coexistence of species in communities. Within a community, the conditions vary more at the scale of the juvenile than of the adult, and juveniles are generally less tolerant of adverse conditions. Here, we are concerned not only with the seedling as defined in a very narrow sense, but also with plants in their first few weeks, months, years, or decades of life - depending on the type of vegetation.

Third, it seemed at one time that a seed number-seedling survival trade-off had considerable potential in explaining the coexistence of species that differ appreciably in seed size but have very 
similar requirements for regeneration. In this event, most researchers have concluded that the trade-off by itself is not enough to explain the coexistence of the full range of seed sizes, either where greater survival results from greater competitive ability or where it results from greater tolerance of hazards during establishment.

Fourth, there has been a greatly increased appreciation that seedlings, more often than not, are in symbiosis with a type of microorganism, most commonly with at least one arbuscular mycorrhizal fungus. Gradually, plant ecologists have come to realize that in one community, some plant species are more dependent on a symbiont than in others, and that symbionts of a given type can have inhibitory as well as stimulatory effects. There have been parallel advances in our knowledge of the seedlings of plants that are partially or wholly parasitic. There remains open the question of how much specialization exists in the relationship between plant species and their symbionts a question that can now be tackled more satisfactorily as a result of the development of molecular techniques.

Fifth, the development of molecular biology has greatly increased the potential for advances in understanding the physiology of seedlings - particularly their tolerances of shade, drought, low nutrient supply, and excess salt. The same goes for our understanding of seedling development, including the part played by phytohormones.

Sixth, there has been a revolution in our thinking about the kinds of seeds of the most primitive angiosperms and the habitats in which they functioned. Also, there has been renewed attention to the earliest true seeds of gymnosperms and the analogous seed-like structures of certain tree lycophytes.

Seventh, in the last two decades, there has been a surge of interest in the long-standing problem of why some species are much more invasive than others and in the related issue of how to restore vegetation at degraded sites. Some of us feel that it is difficult to extract generalizations in these areas, and, in many cases, the key species are idiosyncratic in their requirements. Nevertheless, the great practical importance of the problems makes it imperative that they be tackled by some of the ablest ecologists. Every stage in a plant's life cycle must be considered, but, in many cases, the seedling stage will turn out to be of critical importance.

With this background, we may welcome a new book that covers the whole range of issues I have outlined. An especially attractive feature of the book is that a good many of the schools of thought that have dominated developments in thinking are represented among the authors and, more specifically, that many of the authors have been among those who have taken leading roles in plant ecology in the last two decades.

Studies on seedlings, despite real advances, are still at an immature stage, and there remain significant disagreements. I cannot accept all of the assertions in this book and, indeed, I have argued in print with some of the authors. However, for me, this does not detract 


\section{Cambridge University Press}

978-0-521-87305-5 - Seedling Ecology and Evolution

Edited by Mary Allessio Leck, V. Thomas Parker and Robert L. Simpson

Frontmatter

More information

from the value of the book. I strongly recommend it to all those who seek thoughtful, up-to-date reviews of the wide range of interconnected topics that constitute seedling ecology and ecophysiology.

Peter J. Grubb

Department of Plant Sciences

University of Cambridge

June 2007 


\section{Preface}

Interest in developing this multiauthored book grew from our work with seeds and seed-bank ecology. While seed production and seedbank dynamics are critical stages, what happens to seedlings is also fundamental to explaining field observations of vegetation dynamics and recruitment. Although several recent books discuss seedlings, indicating their importance to plant regeneration (Fenner, 2000) and to seed ecology (Fenner \& Thompson, 2005), only one, Swaine (1996), focuses on seedling ecology; it, however, deals exclusively with tropical forest seedlings and is now more than 10 years old. A fourth volume, Forget et al. (2005), is primarily about seed predation and dispersal. Seedling Ecology and Evolution will complement these works and provide a more all-encompassing discussion. Moreover, it bridges the life-cycle gap following seeds (e.g. Baskin \& Baskin, 1998) and seed banks (e.g. Leck et al., 1989). Additional information about regeneration strategies may be found in Harper (1977), Grubb $(1977,1998)$, and Grime (2001).

We acknowledge the importance of understanding seedling biology in agriculture and horticulture; however, seedlings are well studied in these settings, whereas in natural systems, seedlings are less studied, and the literature is more diffuse. This book explores seedling adaptations and constraints to regeneration in natural and disturbed systems, where a better understanding of seedlings would stimulate study and development of theory regarding this dynamic and often neglected part of the plant life cycle.

After seeds, seedlings typically suffer the highest mortality rate of any life history stage and, therefore, are important in the selection and evolution of species. Seedlings appear to be a "bottleneck" in plant establishment because they are particularly sensitive to the vagaries of the environment. Our purpose is to explore their ecology and evolution and, in the process, bring a diverse literature together for the first time - examining the diverse morphologies and physiologies of seedlings; environmental factors that impact seedlings; driving factors in the evolution of seedlings, including phylogenetic and ecophysiological constraints; seedlings in plant community dynamics, especially how they relate to species and community sustainability; seedling strategies and syndromes, including seedling banks; and the impact of human-generated perturbations, such as invasive species, desertification, and habitat fragmentation and restoration. To accomplish this, contributors were invited to explore a range of topics that are gathered in the book as follows:

- Part I - Introduction. Chapter 1 provides a review of seedling structure, as well as an introduction to the seedling stage of the seed plant life cycle.

- Part II - Seedling diversity. Chapters 2-4 consider aspects of seedling natural history, strategies in stressful habitats where shade, 
drought, inundation, and other stressors affect establishment, and strategies of highly specialized plants, including epiphytes, orchids, and parasites.

- Part III - Seedling morphology, evolution, and physiology. Chapters 5-9 examine seedling evolution in the context of embryo evolution and the rise of angiosperm ecological diversity, as well as seedling morphological and developmental changes, phytohormones, maintenance of carbon balance, and the role of symbioses in establishment and survival.

- Part IV - Life history implications. Chapters 10-13 examine the tradeoffs of the seedling stage with other stages, and seedlings in population and community contexts, as well as functional groups among and within habitats.

- Part V - Applications. Chapters 14-17 examine seedlings as the advancing front for biological invasions, in deteriorating ecosystems (e.g. deserts), in systems in which they are used for system maintenance (forests), and for restoration.

- Part VI - Synthesis. Chapter 18 considers the multiple perspectives presented by the chapters of this book, presents overarching seedling strategies, and summarizes areas for future study.

\section{References}

Baskin, C. C. \& Baskin, J. M. (1998). Seed Ecology, Biogeography, and Evolution of Dormancy and Germination. San Diego: Academic Press.

Fenner, M., ed. (2000). Seeds: the Ecology of Regeneration in Plant Communities. Wallingford: $C A B$ International.

Fenner, M. and Thompson, K. (2005). The Ecology of Seeds. Cambridge: Cambridge University Press.

Forget, P.-M., Lambert, J. E., Hulme, P. E., \& Vander Wall, S. B., ed. (2005). Seed Fate: Predation, Dispersal and Seedling Establishment. Wallingford: CAB International.

Grime, J. P. (2001). Plant Strategies, Vegetation Processes, and Ecosystem Processes. Chichester: John Wiley \& Sons.

Grubb, P. J. (1977). The maintenance of species-richness in plant communities: the importance of the regeneration niche. Biological Reviews, 52, 107-45.

Grubb, P. J. (1998). A reassessment of the strategies of plants which cope with shortages of resources. Perspectives in Plant Ecology, Evolution and Systematics, 1, 3-31.

Harper, J. L. (1977). Population Biology of Plants. London: Academic Press.

Leck, M. A., Parker, V. T., \& Simpson, R. L., ed. (1989). Ecology of Soil Seed Banks. San Diego: Academic Press.

Swaine, M. D., ed. (1996). Ecology of Tropical Forest Seedlings, Man and the Biosphere Series, Vol. 17. Carnforth: UNESCO \& The Parthenon Publishing Group. 


\section{Acknowledgments}

E-mail facilitated interaction with contributors and reviewers from around the world. We are grateful to those who reviewed and improved chapters: Lubomir Adamec, Institute of Botany - Trebon, Czech Republic; Mitch Aide, University of Puerto Rico, USA; Christopher Baraloto, University of Florida, USA; Carol Baskin, University of Kentucky, USA; Margaret Brock, wetland botanist, Tasmania, Australia; Hans Cornelissen, Vrije Universiteit, The Netherlands; Saarad DeWalt, Clemson University, USA; Ian Dickie, Land Care Research, NZ; Joan Ehrenfeld, Rutgers University, USA; Wayne Ferren, Maser Consulting, New Jersey, USA; Lorena Gomez-Aparicio, Universidad de Granada, Spain; Norma Good, botanist, New Jersey, USA; James Grace, United States Geological Survey, Wetlands Center, Louisiana, USA; Denise Hardesty, CSIRO Atherton, Australia; Colleen Hatfield, California State University - Chico, USA; Jose Hierro, Universidad Nacional de La Pampa, Argentina; Patricia Holmes, Cape Ecological Services, South Africa; Enrique Jurado, Universidad Autónoma de Nuevo León, Mexico; Anwar Maun, University of Western Ontario, Canada; Dan Metcalfe, CSIRO Atherton, Australia; Susan Mopper, University of Louisiana, USA; Kazuhide Nara, University of Tokyo, Japan; Susan Schwinning, Texas State University - San Marcos, USA; Anna Sher, University of Denver, USA; John N. Thompson, University of California - Santa Cruz, USA; Larry Tieszen, United States Geological Survey, South Dakota, USA; Barry Tomlinson, Harvard Forest, USA; Eric von Wettberg, University of California - Davis, USA; Michael Walters, Michigan State University, USA; Michael Williams, Butte College, USA; Amy Zanne, National Evolutionary Synthesis Center, North Carolina, USA; and Jess Zimmerman, University of Puerto Rico, USA.

We thank our colleagues, too many to mention, who contributed to the development of our ideas as this book evolved. We are especially grateful to the contributors who willingly devoted their time and creative energies to this book, and for their good humor in meeting deadlines and responding to our numerous queries. We also acknowledge the many others whose work has contributed to our understanding of seedling biology.

Our special thanks go to Jacqueline Garget of Cambridge University Press and Eleanor Umali of Aptara, who shepherded this book to completion; to Marian and Brewster Young, who lent their home in Monterey, California, for a work retreat; and especially to our spouses, Charles F. Leck, Alison Sanders, and Penelope Simpson, for their enthusiastic and enduring support of this project. Finally, we acknowledge the inspiration of particular seedlings, including Impatiens capensis (all); Bidens laevis and Polygonum bistortoides (Leck); Ambrosia trifida, Typha spp., and Zizania aquatica (Simpson); and Arctostaphylos canescens and Grindelia stricta var. angustifolia (Parker). 